\title{
EXTRAÇÃO DE LIPÍDIOS TOTAIS EM AMOSTRA DE SEMENTE DE MARACUJÁ UTILIZANDO DICLOROMETANO
}

\author{
G. G. ALVES ${ }^{1}$, I. B. T. PEREIRA ${ }^{1}$, L. F. SANCHES ${ }^{1}$, F. B. D. MIKALOUSKI ${ }^{1}$, M. C. S. \\ GOMES $^{1}$, C. C. SIPOLI ${ }^{1}$, F. LINI ${ }^{1}$, R. M. SUZUKI ${ }^{1}$ \\ ${ }^{1}$ Universidade Tecnológica Federal do Paraná, Departamento de Engenharia Química \\ E-mail para contato: gigiacobboalves@gmail.com
}

\begin{abstract}
RESUMO - Sementes são ricas em lipídios, com destaque aos poliinsaturados, além de serem fontes de compostos bioativos. A qualidade dos óleos vegetais está relacionada com a presença de compostos bioativos, na qual o seu conteúdo pode variar de acordo com o processo de extração. Para evitar a degradação desses compostos, a extração desses lipídios não deve ser feita a quente. Foi desenvolvido um método de extração de lípidos a frio, utilizando diclorometano, solvente menos nocivo que o clorofórmio que é utilizado no método Bligh \& Dyer. Empregando o novo método, que utiliza diclorometano- água $(3: 1, \mathrm{v} / \mathrm{v})$ e $10 \mathrm{~mL}$ de metanol, obteve-se uma média de $21 \%$ de lipídios totais extraídos da semente de maracujá, não apresentando diferença significativa $(\mathrm{p}<0,05)$ com o método Bligh \& Dyer.
\end{abstract}

\section{INTRODUÇÃO}

As sementes de maracujá, resíduos industriais provenientes do processo de esmagamento da fruta para a obtenção do suco, atualmente são na sua maioria descartadas, gerando resíduo, agregar valor a estes subprodutos é de interesse econômico, científico e tecnológico (Ferrari et al., 2004).

De acordo com Ferrari et al. (2004), as sementes de maracujá possuem em torno de $25,7 \%$ de óleo e teor protéico de 15,62\%, sendo também ricas em fibras. Morais et al. (2015) relata que cascas e sementes podem apresentar maior teor de nutrientes do que a polpa. Sementes são ricas em lipídios, com destaque aos poliinsaturados (Koolen et al., 2013), além de serem fontes de compostos bioativos. Assim, seu consumo pode proporcionar benefícios à saúde, como a prevenção de doenças cardiovasculares, câncer, inflamações, artrites, diabetes, mal de Alzheimer (Koolen et al., 2013).

A qualidade dos óleos vegetais é relacionada com a presença de compostos bioativos, na qual o seu conteúdo pode variar de acordo com o processo de extração. Entretanto, os métodos analíticos empregados para a determinação desses bioativos ainda não estão bem consolidadas. A etapa extração com solvente é o ponto mais crítico para a análise de matéria graxa total, lipídios neutros e polares, e composição ácidos graxos de sementes. Trabalhos científicos, relacionados a sementes de frutas, demonstram que as extrações de lipídios para 
posterior análises de ácidos graxos são realizados através de Soxhlet (Lima, et al. 2014; Gunawan, et al., 2013; Caprioli, et al., 2016) e o por Bligh \& Dyer (Wannes \& Marxouk, 2016; Silva, et al., 2014; Macagnan, et al., 2015).

Soxhlet é um método de extração a quente, não sendo conveniente para a determinação de AG poliinsaturados devido à sua possível oxidação (Biondo et al., 2015), além de extrair somente lipídios livres. Entretanto, o método Bligh \& Dyer (1959) utiliza clorofórmiometanol-água, (2:2:1,8 v/v), para amostras que possuem $80 \%$ de umidade e é capaz de extrair lipídios neutros e polares (Iverson, et al., 2001).

Entretanto, o clorofórmio, solvente orgânico, agente carcinogênico, pode conduzir problemas de saúde aos seres humanos e o metanol pode causar problemas com a visão (Radin, 1981).

Considerando a preocupação global em relação ao uso de solventes orgânicos e aos danos que podem ser causados ao ambiente, o desenvolvimento de métodos alternativos de extração de lipídios e qualidade dos produtos devem ser avaliados. Existe, portanto, a necessidade de desenvolvimento de método analítico de extração de lipídios a frio utilizando solventes menos tóxicos e/ou em menores concentrações de solventes. Assim, este trabalho tem como objetivo a extração de lipídios de semente de maracujá usando diclorometano em substituição ao clorofórmio, usado por Bligh \& Dyer, devido suas vantagens sobre outros solventes, como miscibilidade com água fraca, não inflamabilidade, facilidade de remoção de produtos por evaporação e por ser um dos compostos organoclorados menos nocivos, possui limiar de $50 \mathrm{ppm}$ ou $177 \mathrm{mg}$. $\mathrm{m}^{-3}$ no local de trabalho (Ilo,2009).

\section{METODOLOGIA}

\subsection{Amostragem}

As sementes de maracujá, um resíduo gerado na produção da polpa, foram fornecidas pela empresa Polpa Norte, localizada na cidade de Japurá-Pr. Inicialmente, as sementes foram lavadas em água corrente, secas em estufa e armazenadas em embalagens de polietileno, sob vácuo, em freezer $\left(-18^{\circ} \mathrm{C}\right)$ para posteriores procedimentos e análises.

\subsection{Construção das curvas de solubilidade e extração de lipídios totais}

Os lipídios totais das sementes foram extraídos utilizando dois diferentes métodos: Bligh \& Dyer (1959), que utiliza metanol, clorofórmio e água na razão de 2: 2: 1,8 (v / v / v); e novo método a ser desenvolvido utilizando diclorometano-metanol-água.

Para o novo método foi realizado um estudo utilizando diferentes proporções solventes selecionados (diclorometano, metanol e água) para determinar o melhor desempenho de extração de lipídios totais para a semente de maracujá (Figura 1). 
Figura 1 - Diagrama de fases (\%v/v) diclorometano/metanol/água. Os pontos A, B, C, D, e E formam uma fase para o solvente inicial e os pontos A', B',C', D', E' e A", B”, C", D" e E" formam duas fases na adição de solvente.

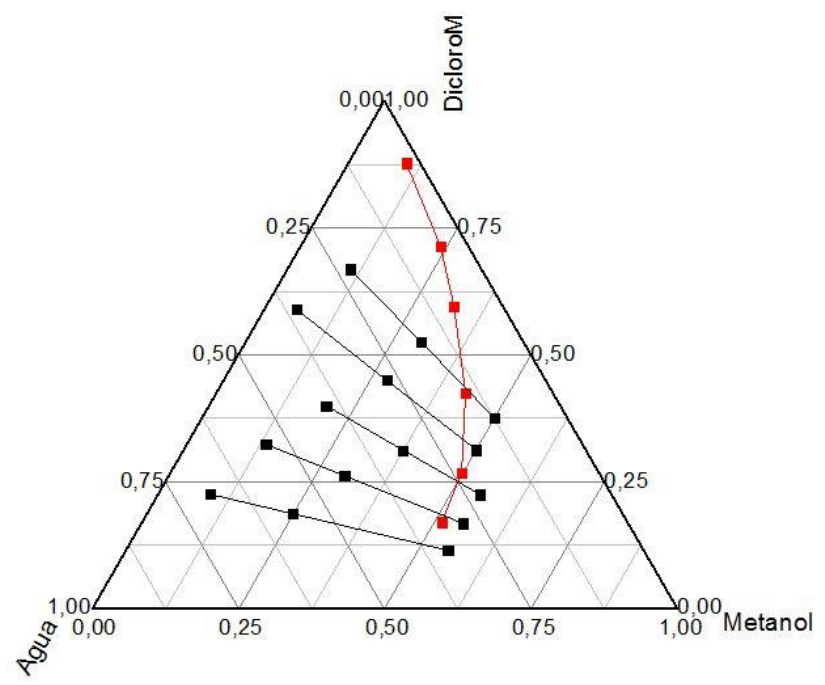

Através do estudo do diagrama ternário de fases (Figura 1), foram analisadas misturas dos solventes em diferentes razões, identificados nos pontos A-A" a E-E”. O solvente inicial formou uma única fase e o solvente adicionado formou duas fases.

O rendimento de lipídios totais das sementes de maracujá foi determinado gravimetricamente de acordo com as razões dos pontos discriminados na Figura 1.

\section{RESULTADOS E DISCUSSÕES}

Através do diagrama ternário de fases foi possível determinar as razões de solventes e os pontos para a análise. Os resultados obtidos em cada ponto foi avaliado pelo diagrama de dispersão (Figura 2), em comparação com os resultados da metodologia proposta por Bligh \& Dyer.

O diagrama de dispersão, retrata a similaridade das extrações de lipídios totais pelo método Bligh \& Dyer e pela nova metodologia proposta. Na qual o solvente extrator clorofórmio foi substituído pelo diclorometano em diferentes proporções. O ponto que apresentou maior concordância com Bligh \& Dyer foi o ponto A-A", não apresentando diferença significativa para o ponto B-B", conforme a Tabela 1, demonstrando, portanto, que o que a melhor razão diclorometano-água foi 3:1(v/v), mantendo o volume de metanol em 10 $\mathrm{mL}$.

Para a escolha de um solvente para a extração é necessário levar em consideração o custo, eficiência de extração, grau de periculosidade ao meio ambiente, toxicidade, disponibilidade, qualidade do produto final e não somente a segurança de operação da extração (Teh Cheng et al., 1991). O solvente diclorometano é considerado não tão tóxico quanto o éter de petróleo, um solvente também utilizado para extrações, e tem um limite 20- 


\section{Congresso Brasileiro de Engenharia Química em Iniciação Científica UFSCar - São Carlos - SP

25 vezes maior (ILO, 2009) do que o clorofórmio, que é usado em outros procedimentos de extração de lipídios, como e Bligh \& Dyer. Cequier-Sanchez et al., (2008) utilizaram diclorometano na extração lipídica de sementes de Echium virescens. Assim, os dados confirmam a possibilidade da substituição do solvente clorofórmio por diclorometano tornando o método menos agressivo ao meio ambiente devido ao clorofórmio ser um solvente poluente em água, fazendo parte do grupo B2, da EPA (Proteção Ambiental Americana) em relação ao solvente orgânico diclorometano, que possui menor impacto ambiental além do menor custo de solvente.

Figura 2 - Diagrama de dispersão do teor de lipídios em função da quantidade de água e solvente extrator (clorofórmio / diclorometano).

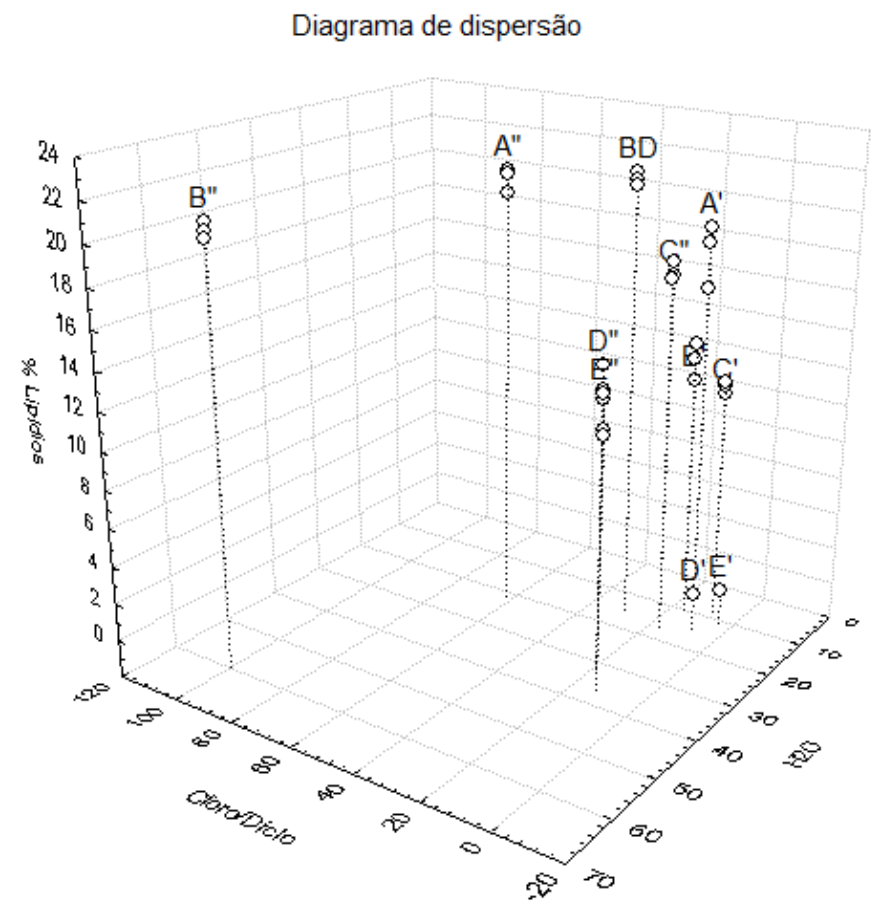




\section{Congresso Brasileiro de Engenharia Química em Iniciação Científica UFSCar - São Carlos - SP

Tabela 1- Lipídios Totais $\left(\mathrm{g} 100 \mathrm{~g}^{-1}\right.$ ) presentes em sementes de maracujá obtidos pelo método

Bligh \& Dyer e pelas extrações utilizando mistura de diclorometano-metanol-água em diferentes pontos

\begin{tabular}{|c|c|}
\hline Extração & Lipídios (g/100g amostra) \\
\hline Bligh \& Dyer & $17,3395^{\mathrm{b}} \pm 0,3313$ \\
\hline A-A & $17,3395^{\mathrm{c}} \pm 1,6886$ \\
\hline A-A" & $21,0730^{\mathrm{b}} \pm 0,5791$ \\
\hline B-B' & $12,0576^{\mathrm{a}} \pm 0,9689$ \\
\hline B-B” & $20,4641^{\mathrm{b}} \pm 0,4072$ \\
\hline C-C' & $10,7705^{\mathrm{a}} \pm 0,3226$ \\
\hline C-C' & $17,2987^{\mathrm{c}} \pm 0,4674$ \\
\hline D-D' & ---- \\
\hline D-D” & $13,0722^{\mathrm{a}} \pm 0,8687$ \\
\hline E-E' & ---- \\
\hline E-E” & $12,1387^{\mathrm{a}} \pm 1,1314$ \\
\hline
\end{tabular}

Resultados expressos como média \pm desvio padrão $(n=3)$. Letras diferentes indicam diferença significativa pelo teste Tukey $(\mathrm{p}<0,05)$.

\section{CONCLUSÃO}

Foi possível concluir a partir dos dados relatados que o diclorometano pode ser utilizado como solvente extrator de lipídios totais em amostras de semente de maracujá em substituição ao solvente clorofórmio utilizado no método Bligh \& Dyer.

\section{REFERENCIAS}

Biondo, P. F., Santos, V. J., Montanher, P. F., Junior, O. O. S., Matsushita, M., Almeida, V. C., Jesuí, V. V., Analytical Methods, 7, 9773-9778. 2015.

Bligh, E.G., Dyer, W.J. (1989). A rapid method of total lipid extraction and purification. Canadian Journal of Biochemistry and Physiology, 37, 911-917.

Caprioli, G., Iannarelli, R., Cianfaglione, K., Fiorini, D., Lucarini, D., Papa, F., Food Research International, 79, 1-10. 2016. 


\section{Congresso Brasileiro de Engenharia Química \\ em Iniciação Científica \\ UFSCar - São Carlos - SP

Cequier-Sanchez, E., Rodriguez, Ravelo, A., Zarrate, R., 2008. Dichloromethane as a solvent for lipid extraction and assessment of lipid classes and fatty acids from samples of different natures. Journal of Agricultural and Food Chemistry, 59 (12), 4297-4303.

Koolen, H.H.F., Silva, F.M.A., Gozzo, F.C., Souza, A.Q.L., Souza, A.D.L. (2013). Antioxidant, antimicrobial activities and characterization of phenolic compounds from buriti (Mauritia flexuosa L. f.) by UPLC-ESI-MS/MS. Food Research International, $51,467-473$.

Ferrari, R.A., et al., Revista Brasileira de Fruticultura, 26, 101-102. 2004.

International Labor Organization (ILO), 2009). Belgium, Ministry of Employment and Work, Annex 1, Arre`te' royal du 11 mars 2002 relatif a' la protection de la sante' et de la se'curite' des travailleurs contre les risques lie's a` des agents chimiques sur le lieu de travail. Occupational Exposure Limits Home Page: http://www.ilo.org/

Iverson, S. J., Lang, S. L. C., Cooper, M. H., Lipids, 2001, 36,1283- 1287. 2001.

Gunawan, S., Darmawan, R., Nanda, M., Setiawan, A. D., Fansuri, H., Industrial Crops and Products 4, 107-112. 2013.

Lima, B.N.B., Lima, F.F., Tavares, M. I. B., Costa, A. M. M., Pieuricci, A. P. T. R., Food Chemistry, 151, 293-299. 2015.

Macagnan, F.T., Santos, L.R., Roberto, B.S., Moura, F.A., Bizzani, M., Silva, L.P. (2015). Biological properties of apple pomace, Orange bagasse and passion fruit peel as alternative sources of dietary fibre, Bioactive Carbohydrates and Dietary Fibre, 6, 1-6.

Morais, D.R., Rotta, E.M., Sargi, S.C., Schimidt, E.M., Bonafé, E.G., Eberlin, M.N., Sawaya, A.C.H.F., Visentainer, J.V. (2015). Antioxidant activity, phenolics and UPLC-ESI(-)-MS of extracts from diferente tropical fruits parts and processed peels. Food Research International, 77, 392-399.

Radin, N. S., Methods in Enzymology, ed. J. Lownstein, Academic Press, New York, vol. 72, p. 5. 1981.

Silva, A.C., Jorge, N. (2014). Bioactive compounds of the lipid fraction of agroindustrial waste, 66, 493-500.

Teh Cheng Lo, Malcolm H I Baird. Handbook of Solvent extraction, p.593-597, 1991.

Wannes, W.A., Marzouk, B. (2016). Characterization of myrthe seed (myrtus communis var. baetica) as a source of lipids, phenolics, and antioxidante activities. Journal of Food na Druy Analyses, I18, 1-8. 